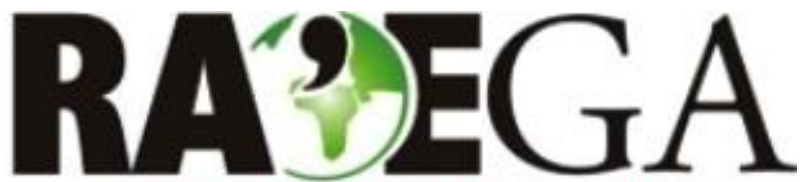

O ESPAÇO GEOGRÁFICO EM ANÁLISE

\title{
A INFLUÊNCIA DO VENTO REGIONAL NA SENSAÇÃO TÉRMICA DE PEDESTRES EM ESPAÇOS URBANOS ABERTOS: ESTUDO DE CASO DO VENTO NORTE EM SANTA MARIA-RS
}

\section{THE INFLUENCE OF REGIONAL WIND ON THERMAL SENSATION OF WALKING IN OPEN URBAN SPACES: CASE STUDY OF THE NORTH WIND IN SANTA MARIA-RS}

\author{
João Paulo Assis Gobo ${ }^{1}$, Rogério Rozolen Alves ${ }^{2}$, Thiago Souza Silveira ${ }^{3}$, Daniela de Souza Onça ${ }^{4}$, \\ Leonardo Marques Monteiro ${ }^{5}$, Cássio Arthur Wollmann ${ }^{6}$, Emerson Galvani ${ }^{7}$, \\ RESUMO
}

Atualmente, existem poucos estudos sobre a influência do vento no ambiente térmico exterior e no conforto térmico em áreas urbanas de clima subtropical. As atuações de ventos regionais típicos são de grande importância na interpretação de dados e na busca por respostas perceptivas e de sensação térmica da população. A presente pesquisa buscou por meio da análise de dados climáticos obtidos em campo, avaliar a sensação térmica e a percepção climática da população de Santa Maria-RS, sob influência do vento norte local, um vento regional típico que se caracteriza por ser quente e seco e soprar do quadrante norte em períodos de tempo pré-frontal. Para tanto, fez-se o uso de dados meteorológicos primários, a partir da instalação de uma estação meteorológica móvel no centro da cidade, bem como de dados meteorológicos secundários, provenientes da Estação Meteorológica de Santa Maria sob responsabilidade do Instituto Nacional de Meteorologia (INMET). Também foram executadas entrevistas com a população local, com a finalidade de obter as respostas perceptivas e de sensação térmica dos usuários que circulavam em ambiente urbano. Verificou-se uma influência negativa do vento norte na sensação térmica da maioria dos indivíduos entrevistados, bem como uma percepção desfavorável ao vento, o que resultou em sensação térmica de desconforto durante os dias em que as temperaturas estavam elevadas e o vento norte quente e seco mais intenso.

PALAVRAS-CHAVE: conforto térmico; percepção; sensação térmica.

\section{ABSTRACT}

Currently, there are few studies on the influence of wind on outdoor thermal environment and thermal comfort in subtropical climate urban areas. The performances of typical regional winds are of great importance in the interpretation of data and search for population perceptual responses and thermal sensation. This research sought, through analysis of climate data obtained in field, to assess the thermal sensation and climate perception of Santa Maria-RS population, under the influence of the local north wind, a typical regional wind that is characterized by being warm and dry and blowing from the north quadrant in prefrontal episodes. Therefore, we used primary meteorological data, from the installation of a mobile weather station at city center, as well as secondary meteorological data from Santa Maria weather station under the responsibility of the National Institute of Meteorology (INMET). Interviews were also carried out with the local population, in order to get the perceptual and thermal sensation responses of users circulating in the urban environment. There was a negative influence of the north wind in the thermal sensation of the majority of the interviewees, as well as an unfavorable perception of the wind, resulting in thermal discomfort during the days when temperatures were high and hot dry north wind more intense.

KEY-WORDS: thermal comfort; perception; thermal sensation.

Recebido em: 23/03/2016

Aceito em: 17/10/2016

\footnotetext{
${ }^{1}$ Universidade de São Paulo, São Paulo/SP, e-mail: jpgobo@usp.br

${ }^{2}$ Universidade de São Paulo, São Paulo/SP e-mail: rroz@usp.br

${ }^{3}$ Universidade de São Paulo, São Paulo/SP, e-mail: thiagosousilveira@yahoo.com.br

${ }^{4}$ Universidade do Estado de Santa Catarina,Florianopolis/SC e-mail: danielaonca@yahoo.com.br

${ }^{5}$ Universidade de São Paulo, São Paulo/SP, e-mail: leo4mm@gmail.com

${ }^{6}$ Universidade Federal de Santa Moria, Santa Maria/RS, e-mail: cassio_geo@yahoo.com.br

${ }^{7}$ Universidade de São Paulo, e-mail: egalvani@usp.br
} 
GOBO,J.P.A., ALVES,R.R., SILVEIRA,T.S., ONÇA,D.S.,MONTEIRO,L.M., WOLLMANN,C.A. e GALVANI,E. A INFLUÊNCIA DO VENTO REGIONAL NA SENSAÇÃO TÉRMICA DE PEDESTRES EM ESPAÇOS URBANOS ABERTOS: ESTUDO DE CASO DO VENTO NORTE EM SANTA MARIA-RS

\section{INTRODUÇÃO}

Os efeitos fisiológicos dos ventos sempre foram considerados importantes na história da humanidade. Em quase todas as regiões do mundo existe uma expressão ou palavra, de cunho regional, para designar um tipo especial de vento, principalmente quentes e secos. Por exemplo, na Itália é o Siroco, o "pai da depressão"; na Espanha é o Leveccio; no Egito tem o Chamsin; na Argentina, o Zonda; na França há o Autan e o Mistral; o Saara tem o Simoon, enquanto o Sharav e o Chamsin são encontrados no Oriente Médio e em Israel; no Havaí sopra o Kona; na Noruega, o Bora; na Áustria, o Föhn; em Salzburg há o Tauerwind; no Danúbio superior, o Pyrnwind; Lyon sofre com o Vento de Midi; a Califórnia, com o Santa Ana; no leste das Montanhas Rochosas e no noroeste do Canadá sopra o Chinook (SARTORI, 2016).

A bioclimatologia trata da camada de ar mais próxima do homem, considera para seus estudos somente a camada superficial, que se estende até aproximadamente 100 metros acima da superfície do solo. As trocas de calor por convecção são ativadas pela velocidade do ar, quando se trata de superfícies verticais. Nesse caso, mesmo que o movimento do ar advenha de causas naturais, como o vento, o mecanismo de troca entre a superfície e o ar passa a ser considerado de convecção forçada (FROTA; SCHIFFER, 2001).

O vento exerce ação dinâmica e refrescante no corpo humano, às vezes negativa, e o aspecto mais importante a esse respeito refere-se a sua velocidade. De forma geral, os ventos continentais frios ou quentes, violentos e secos, são nocivos ao corpo humano, pois ressecam e racham a pele, irritam os brônquios, provocam tosse e tornam difícil a expectoração. Por outro lado, os ventos marinhos, úmidos e regulares, em geral, são mais favoráveis à saúde (SARTORI, 2000).

Sorre (1984) relata em seus primeiros estudos que as disposições nervosas e os estados mentais são influenciados pelos movimentos da atmosfera, o tegumento e as terminações nervosas sentem estas variações. O autor chama atenção ao fato de exploradores de regiões polares suportarem temperaturas inferiores a 40 ㅇ C sem vento, no entanto padecerem sob temperaturas de $-10^{\circ} \mathrm{C}$, mas com ventos com velocidade elevada.

Sob vento forte com velocidade elevada, a pele humana transmite avisos de sofrimento ao cérebro; quando o vento domina as condições de tempo, as pessoas tempo-sensitivas parecem se tornar emocionalmente desorientadas. Mesmo brisas moderadas podem ser problemáticas para aqueles com enfermidades respiratórias, pois transportam poeira, poluentes, polens e outros alérgicos. A maioria das pessoas também não gosta de ar calmo, pois pode preceder tempestades, afetando-as psicológica e/ou fisicamente (BEDFORD; WARNER, 1934).

Assim, em ambientes urbanos, complexos, o vento pode tornar-se agente de desconforto aos habitantes, pois modifica o vestuário e influencia a forma como o saldo de radiação é utilizado nos diferentes processos associados à incidência de radiação solar, alterando os mecanismos de troca de calor do corpo humano com o ar ambiente, por exemplo. Dessa forma, caracterizar e compreender a circulação atmosférica na escala regional é fundamental na individualização do clima de qualquer lugar e, portanto, indispensável na definição dos tipos de tempo, em sua sucessão habitual ou nos seus distúrbios de comportamento.

No caso do Vento Norte na cidade de Santa Maria no Rio Grande do Sul, este caracteriza-se por ser um vento quente e seco, com direção norte, de velocidade moderada a regular, associado ao ar oriundo da Massa Polar Modificada, da Massa Tropical Atlântica ou da Massa Tropical Continental, que influencia o centro-sul do Brasil, atraído pelas baixas pressões no sul do país, Argentina ou Uruguai, que antecedem a passagem da Frente Polar Atlântica (SARTORI, 2000). A autora ressalta as características particulares assumidas pelo Vento Norte em Santa Maria devido a condicionantes 
GOBO,J.P.A., ALVES,R.R., SILVEIRA,T.S., ONÇA,D.S.,MONTEIRO,L.M., WOLLMANN,C.A. e GALVANI,E. A INFLUÊNCIA DO VENTO REGIONAL NA SENSAÇÃO TÉRMICA DE PEDESTRES EM ESPAÇOS URBANOS ABERTOS: ESTUDO DE CASO DO VENTO NORTE EM SANTA MARIA-RS

geoambientais locais, representados, principalmente pelo relevo e pela posição da cidade no sopé do rebordo do Planalto da Bacia do Paraná, bem como a percepção climática deste vento pela população urbana e rural.

Por percepção ambiental e climática pode-se entender como o processo resultante da interação entre os sentidos humanos e os fenômenos ocorridos no meio ambiente capazes de produzir sensações psico-fisiológicas, criando um sistema de valores, atitudes e sensações do homem para com seu meio (TUAN, 1980; MACHADO, 1996; SARTORI, 2000).

Entretanto, no meio urbano, espaço alvo de estudo nesta pesquisa, a relação do homem com o meio natural é quase inexistente vista tamanha transformação do espaço pelo processo de urbanização. Nesse contexto, a percepção passa a ser menos apurada em relação aos fenômenos naturais, pois, as percepções ambientais e climáticas estão muito mais relacionadas aos impactos que as condições atmosféricas, em geral negativas, têm sobre as atividades espaciais humanas no seu cotidiano, conforme abordam Monteiro (1976) e Sartori (2000), especialmente as relacionadas ao vestuário e deslocamento (forma de transporte/locomoção utilizado).

Partindo destas premissas, o presente estudo buscou avaliar a sensação térmica da população da cidade de Santa Maria no Rio Grande do Sul, sob influência de episódio de vento norte em situação de onda de calor no período de inverno de 2015.

\section{CARACTERIZAÇÃO DA ÁREA DE ESTUDO}

O município de Santa Maria está situado na Depressão Periférica Sul-rio-grandense, entre - Escudo Sul-rio-grandense e o Planalto Meridional Brasileiro, mais precisamente no sopé do rebordo desse Planalto, na região central do estado (Figura 1) (MÜLLER FILHO, 1970).

Essa particularidade associada às causas de cunho dinâmico-climáticas faz com que Santa Maria seja conhecida na região e no Rio Grande do Sul como a cidade do "Vento Norte", característica também conhecida em outros estados do Brasil (SARTORI, 2000).

Dentre os ventos regionais e/ou locais que atuam no Rio Grande do Sul, o Vento Norte é um dos dois tipos de vento que maior impacto provoca sobre a população no território gaúcho e foi o principal elemento climático, com característica regional e/ou local, considerado na análise da percepção do clima (MARIANTE, 1985).

Verifica-se que o Vento Norte em Santa Maria deve ser explicado através de dois grupos de fatores: os genéticos, que correspondem às escalas zonal e regional, e os de integração geoambiental, definidos na escala local (SARTORI, 2016).

Do ponto de vista genético, está associado ao ar oriundo da Massa Polar Modificada, da Massa Tropical Atlântica continentalizada ou da Massa Tropical Continental, que influencia o centro-sul do Brasil, atraído pelas baixas pressões pré-frontais no sul do país, Argentina ou Uruguai, que antecedem a Frente Polar Atlântica (SARTORI, 2000; FAVERA, et al., 2012; MILLER, 1968; PERETTI; SARTORI, 2001; GOBO, et al., 2008). 
GOBO,J.P.A., ALVES,R.R., SILVEIRA,T.S., ONÇA,D.S.,MONTEIRO,L.M., WOLLMANN,C.A. e GALVANI,E. A INFLUÊNCIA DO VENTO REGIONAL NA SENSAÇÃO TÉRMICA DE PEDESTRES EM ESPAÇOS URBANOS ABERTOS: ESTUDO DE CASO DO VENTO NORTE EM SANTA MARIA-RS

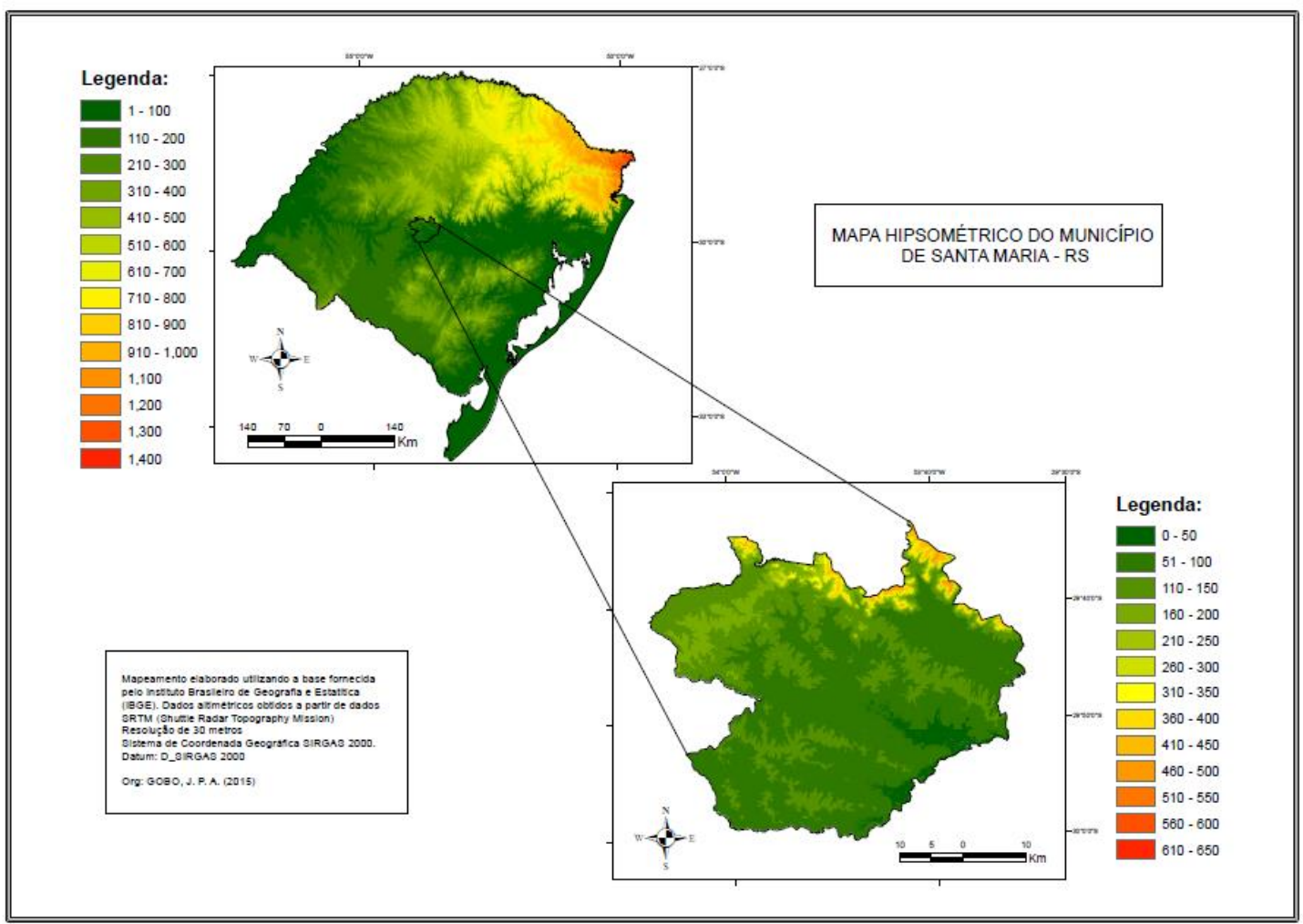

Figura 01 - Localização da área de estudo e Mapa hipsométrico do Rio Grande do Sul e do município de Santa Maria. Org: Os autores.

Do ponto de vista geoambiental, este ganha características particulares em Santa Maria devido a condicionantes geoambientais locais, representadas principalmente pelo relevo e pela posição da cidade no sopé do rebordo do Planalto da Bacia do Paraná que, em face do desnível de aproximadamente $500 \mathrm{~m}$ entre o sítio urbano da cidade e o rebordo do planalto (Figura
1, 2a e 2b), que proporciona um processo de compressão adiabática ao vento que, por conseguinte, apresenta uma elevação de sua temperatura e aumento de velocidade (SARTORI, 2000). 
GOBO,J.P.A., ALVES,R.R., SILVEIRA,T.S., ONÇA,D.S.,MONTEIRO,L.M., WOLLMANN,C.A. e GALVANI,E. A INFLUÊNCIA DO VENTO REGIONAL NA SENSAÇÃO TÉRMICA DE PEDESTRES EM ESPAÇOS URBANOS ABERTOS: ESTUDO DE CASO DO VENTO NORTE EM SANTA MARIA-RS

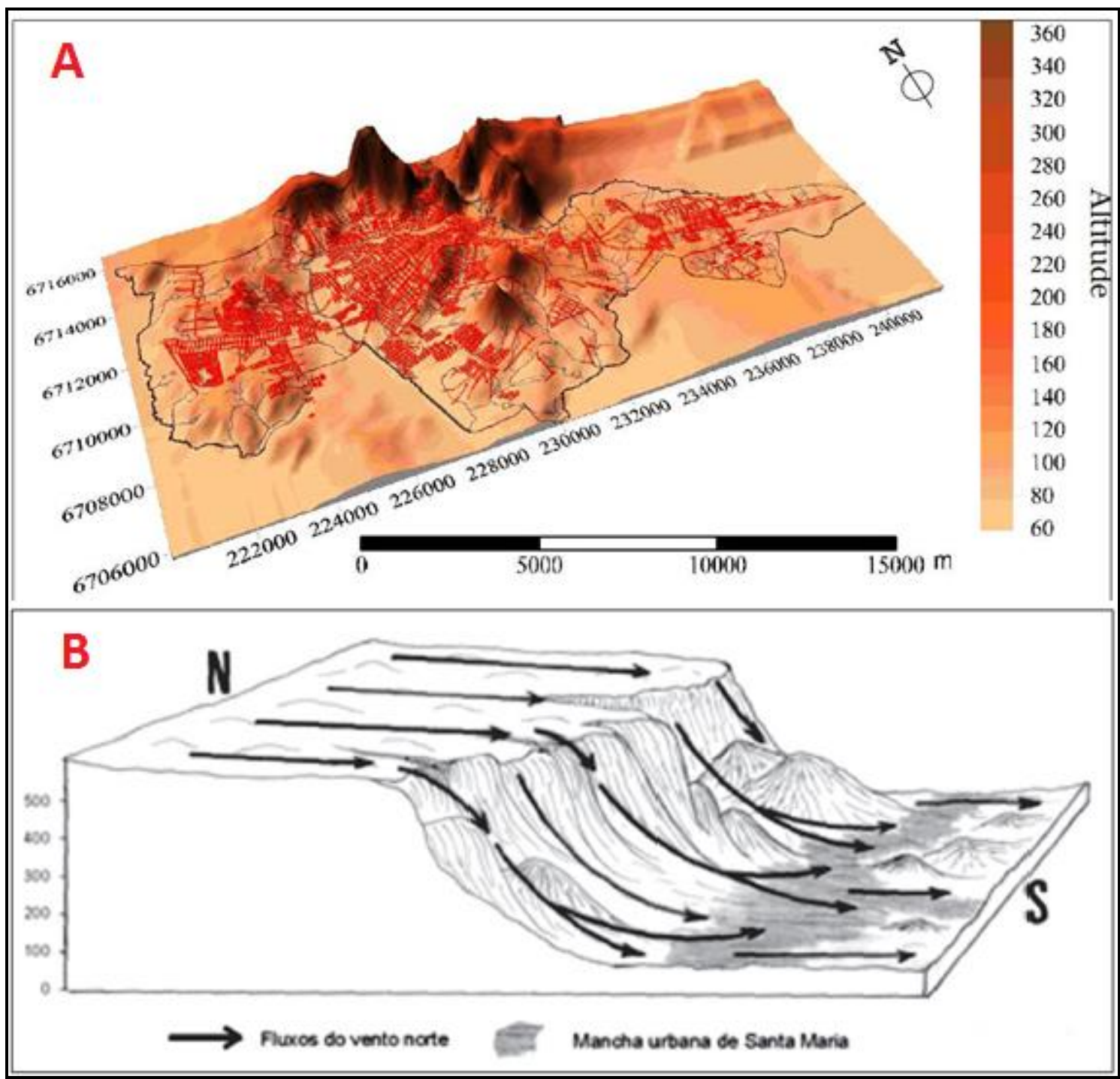

Figura 02 - A - Hipsometria tridimensional da área urbana de Santa Maria. B - O Vento Norte regional, as alterações de fluxo por influência do relevo e a localização da mancha urbana de Santa Maria.Fonte: Dal'Asta. (2007), p.52. Sartori (2000).

\section{MATERIAIS E MÉTODOS}

Para executar a proposta de quantificar as relações entre os aspectos climatológicos da área de estudo e as variáveis subjetivas dos usuários, com a finalidade de estabelecer o grau de sensação térmica da população em relação ao vento norte, fez-se uso do método indutivo experimental, calcado no levantamento de dados climatológicos primários em campo e de variáveis individuais e subjetivas para uma população adaptada à condição climática em que se encontra.
No decorrer da elaboração das premissas fundamentais de esenvolvimento desta pesquisa, optou-se pela utilização de dados primários e, para tanto, fez-se uso de uma estação meteorológica móvel que possibilitou a coleta desses dados na área de estudo.

Assim, foi utilizada uma estação meteorológica de marca Campbell CR-1000 com altura máxima de 2,0m em tripé móvel de alumínio (Figura 3), contendo os seguintes sensores:

$\checkmark \quad$ Pluviômetro de Báscula; 
GOBO,J.P.A., ALVES,R.R., SILVEIRA,T.S., ONÇA,D.S.,MONTEIRO,L.M., WOLLMANN,C.A. e GALVANI,E.

\section{A INFLUÊNCIA DO VENTO REGIONAL NA SENSAÇÃO TÉRMICA DE PEDESTRES EM ESPAÇOS URBANOS ABERTOS: ESTUDO DE CASO DO VENTO NORTE EM SANTA MARIA-RS}

\author{
$\checkmark \quad$ Sensor de Radiação Global; \\ $\checkmark$ Sensor de Temperatura e Umidade \\ do Ar; \\ $\checkmark \quad$ Sensor de Velocidade e Direção do \\ Vento; \\ $\checkmark \quad$ Termômetro de Globo Cinza.
}

Foram coletados dados primários de temperatura do ar (máxima, mínima e média), temperatura de globo cinza - uma vez que a estação ficou estabelecida em área aberta com incidência de radiação solar direta (ISO 7726, 1998) - umidade relativa do ar (máxima, mínima e média), velocidade do vento, rajada do vento, radiação solar global e precipitação.
Os sensores de temperatura do ar, umidade relativa do ar e radiação solar estavam posicionados a uma altura de $1,5 \mathrm{~m}$ do solo, enquanto o sensor de velocidade e direção do vento ficava estabelecido a $2,0 \mathrm{~m}$ de altura no topo da estrutura. No entanto, devido à impossibilidade de reestruturação da estação meteorológica para a pesquisa, esta não estava de acordo com a norma ISO 7726 (1998), que recomenta uma altura média ente $0,6 \mathrm{~m}$ e $1,1 \mathrm{~m}$, próxima ao centro de gravidade do corpo humano.

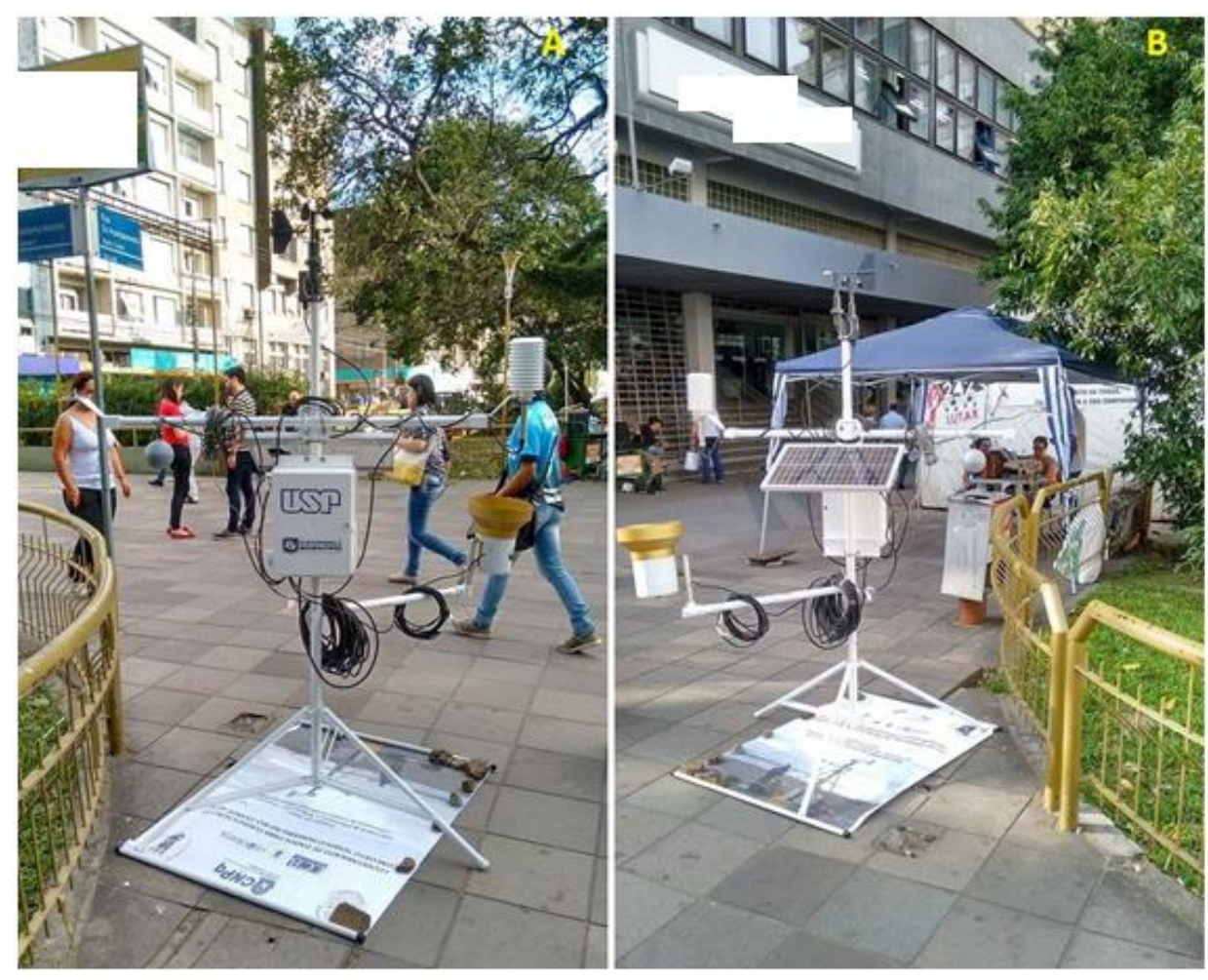

Figura 03 - Estação meteorológica Campbell CR-1000 (Visada norte A; Visada sul B).Org: Os autores.

A estação meteorológica foi instalada em uma área pavimentada da Praça Saldanha Marinho, no centro da cidade de Santa Maria, onde transita um fluxo intenso de pessoas (Figura 3), e os dados eram registrados a cada 10 (dez) minutos.

O período de coletas em campo foi entre os dias 03 de agosto a 07 de agosto de 2015, sendo feitas coletas de dados meteorológicos e entrevistas com a população local entre às 09:00h e 17:00h em cada um dos referidos dias da pesquisa.

Foram entrevistadas 6 (seis) pessoas a cada 10 (dez) minutos (em conformidade com o período de registro dos dados meteorológicos pela estação), totalizando 36 pessoas 
GOBO,J.P.A., ALVES,R.R., SILVEIRA,T.S., ONÇA,D.S.,MONTEIRO,L.M., WOLLMANN,C.A. e GALVANI,E.

\section{A INFLUÊNCIA DO VENTO REGIONAL NA SENSAÇÃO TÉRMICA DE PEDESTRES EM ESPAÇOS URBANOS ABERTOS: ESTUDO DE CASO DO VENTO NORTE EM SANTA MARIA-RS}

entrevistadas a cada hora, 288 (duzentos e oitenta e oito) pessoas entrevistadas nas 8 (oito) horas de coleta de dados para cada dia e 1440 (mil quatrocentos e quarenta) pessoas entrevistadas ao final dos 5 (cinco) dias de trabalho de campo.

Definiu-se que seriam efetivamente entrevistadas apenas pessoas residentes no município a mais de 1 (um) ano, em função do histórico térmico dos indivíduos e da memória ambiental dos mesmos, como foi alertado na pesquisa de Nikolopoulou (2001).

Também foram limitadas as entrevistas a pessoas com idade entre 20 e 60 anos, que não aparentavam sobrepeso e/ou subpeso, com padrão de área de corpo coberta estabelecido entre 0,5 e 1,0 clo, o que correspondem, respectivamente, a um indivíduo de calça jeans e camiseta e um indivíduo de terno (ISO 9920, 2007), com um padrão de atividade física de 300W para cada indivíduo entrevistado, uma vez que só foram entrevistadas pessoas em movimento (caminhando) (ISO 8996, 2004).

Quanto ao questionário aplicado, foi utilizado o modelo estabelecido pela norma ISO 10551 (1995):

Dados do entrevistado: idade (__ ); Sexo ( )M ( JF; Peso (__ ); Altura (__). Com relação à vestimenta do indivíduo ele esta vestindo:

$$
\begin{aligned}
& \text { ( ) } 0,4 \text { clo } \\
& \text { ( ) } 0,5 \text { clo } \\
& \text { ( ) } 1,0 \text { clo } \\
& \text { ( ) } 4,0 \text { clo }
\end{aligned}
$$

1. Neste exato momento, com relação às condições climáticas, eu estou:

( ) confortável

( ) um pouco desconfortável

( ) desconfortável

( ) muito desconfortável

2. Neste exato momento, com relação às condições climáticas, na minha opinião estar neste local é:
( )Perfeitamente tolerável
()Facilmente tolerável
( )Dificilmente tolerável
( )Intolerável

4. Com relação ao vento, eu preferiria que este estivesse:

( ) mais fraco ( ) como está ( ) mais forte ( ) não sei dizer

Após o fim dos cinco dias de coleta de dados meteorológicos e aplicação dos questionários no centro da cidade de Santa Maria, efetuou-se o levantamento dos dados da Estação Meteorológica de Santa Maria, de responsabilidade do Instituto Nacional de Meteorologia (INMET), com a finalidade de obter os registros representativos do clima regional.

De posse dos dados climáticos da EMAINMET de Santa Maria, foi construído o gráfico de Análise Rítmica, com o auxílio do software RITMOANÁLISE (BORSATO; BORSATO; SOUSA, 2004), para fazer o diagnóstico da situação atmosférica regional durante o período de coleta.

Atenta-se para o fato de que foram realizadas investigações apenas em relação aos sistemas atmosféricos (massas e ar e sistemas produtores de chuva) envolvidos, identificandoos com o auxílio de cartas sinóticas e imagens de satélite dos dias de coleta obtidos através do banco de dados do CPTEC/INPE.

Após a interpretação do tempo atmosférico para os dias da pesquisa, o dados meteorológicos da EMA-Móvel foram utilizados para o cálculo do Índice de Temperatura Efetiva com Vento de Suping et al. (1992), para se ter uma noção preliminar da relação entre o conforto térmico humano e o Vento Norte na resposta perceptiva da população.

Quanto aos dados da percepção térmica da população, obtidos a partir das entrevistas em paralelo aos levantamentos meteorológicos, estes foram dispostos em planilhas do software Microsoft Office Excel 2007 e as diferentes respostas subjetivas do questionário receberam um valor numérico de acordo com a escala da ASHRAE/ANSI 55 (2013) que varia entre -3, -2, -1, $0,1,2$ e 3 referentes às respostas perceptivas de: Muito Frio -3; Frio -2; Um Pouco De Frio-1; Nem Frio Nem Calor 0; Um Pouco De Calor 1; Calor 2; Muito Calor 3. 
GOBO,J.P.A., ALVES,R.R., SILVEIRA,T.S., ONÇA,D.S.,MONTEIRO,L.M., WOLLMANN,C.A. e GALVANI,E. A INFLUÊNCIA DO VENTO REGIONAL NA SENSAÇÃO TÉRMICA DE PEDESTRES EM ESPAÇOS URBANOS ABERTOS: ESTUDO DE CASO DO VENTO NORTE EM SANTA MARIA-RS

Em seguida os dados foram submetidos ao cálculo de frequência para identificar qual a resposta preditiva de maior frequência a cada 10 (dez) minutos, período correspondente a tomada de registro dos dados meteorológicos pela EMAMóvel e de 6 (seis) aplicações de questionários a população.

Por fim, fez-se a comparação entre a "Temperatura Efetiva com Vento" calculada a partir dos dados meteorológicos levantados em campo e a percepção térmica da população.

\section{ANÁLISE DOS RESULTADOS \\ 4.1ANÁLISE CLIMÁTICA EM ESCALA REGIONAL}

No dia 03 de agosto de 2015, dia em que se iniciaram as coletas de dados em campo em Santa Maria, observava-se uma frente fria atuando desde o noroeste da Argentina, parte central do Uruguai e estendendo-se pelo oceano Atlântico adjacente até uma área de baixa pressão relativa de $1008 \mathrm{hPa}$ no oceano e uma frente oclusa com centro de baixa pressão de 996 hPa (Figura 4A).

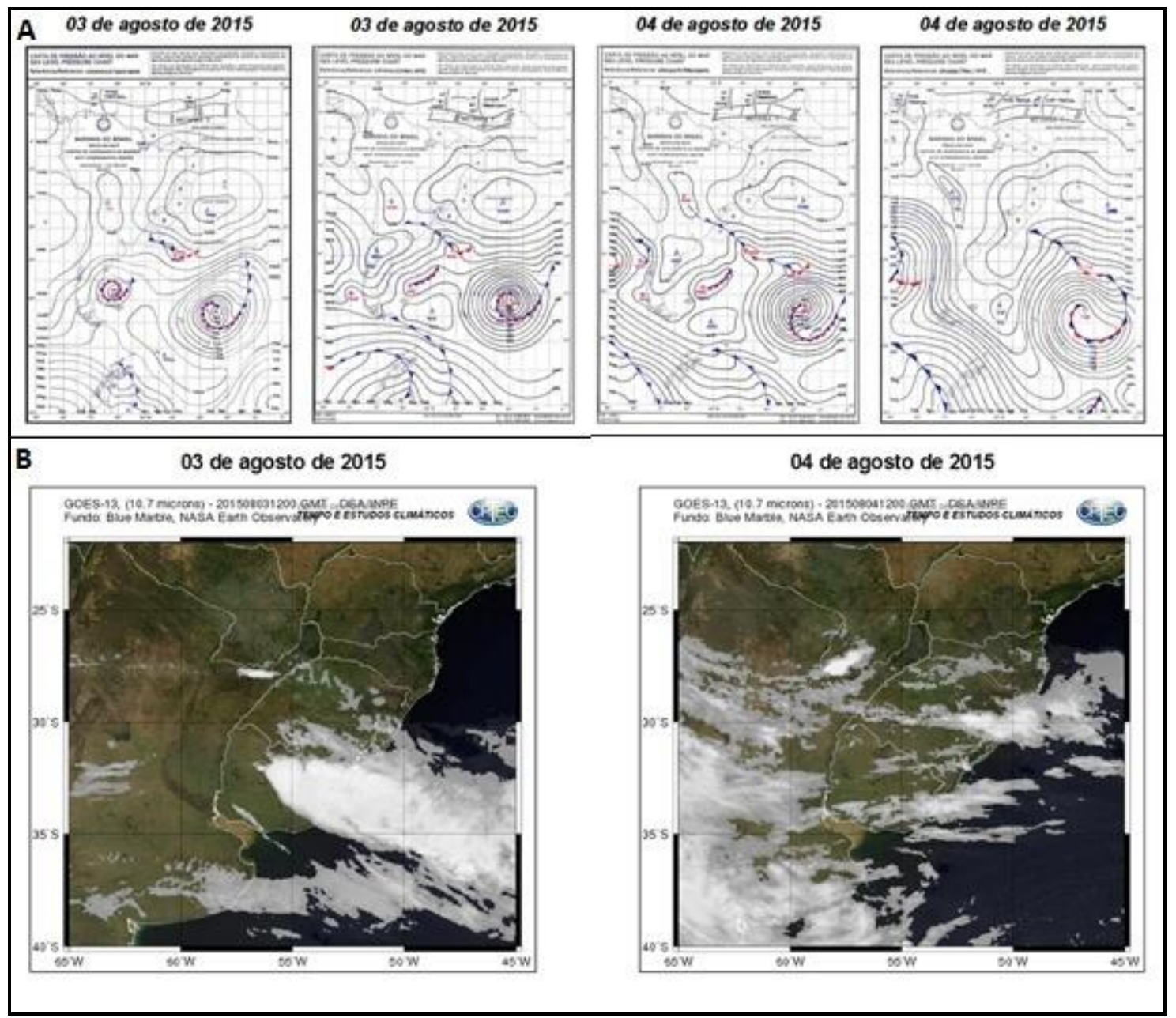

Figura 04 - A - Cartas sinóticas de superfície dos dias 3 e 4 de agosto de 2015. B - Imagens do satélite Goes12 para os dias 3 e 4 de agosto de 2015. Fonte: A Marinha do Brasil (2015). B - - CPTEC/INPE (2015).

Sobre o Rio Grande do Sul observa-se a atuação da Alta Subtropical do Atlântico Sul (ASAS) ou Massa Tropical Atlântica (MTA) com valor de pressão em seu núcleo de valor de 1024 $\mathrm{hPa}$, caracterizando condição de vento do quadrante norte-nordeste para o estado e uma 
GOBO,J.P.A., ALVES,R.R., SILVEIRA,T.S., ONÇA,D.S.,MONTEIRO,L.M., WOLLMANN,C.A. e GALVANI,E. A INFLUÊNCIA DO VENTO REGIONAL NA SENSAÇÃO TÉRMICA DE PEDESTRES EM ESPAÇOS URBANOS ABERTOS: ESTUDO DE CASO DO VENTO NORTE EM SANTA MARIA-RS

condição pré-frontal bem definida com pressão atmosférica baixa, de $997 \mathrm{hPa}$.

No decorrer do dia 03 de agosto a frente avançou sobre o Rio Grande do Sul e na análise da carta sinótica de superfície das $12 Z$ do dia 03, observa-se a frente fria atuando desde o noroeste da Argentina, passando pelo RS e se estendendo pelo oceano com um pulso de alta pressão de 1016 hPa na retaguarda da frente. $\mathrm{Na}$ imagem do satélite GOES12 para às 00:00h do dia 03 de agosto, no entanto, não é possível observar ainda a frente sobre o Rio Grande do Sul (Figura $4 B)$.

No dia seguinte, 04 de agosto de 2015, observa-se uma frente estacionária atuando desde o noroeste da Argentina, norte do Uruguai e estendendo-se como frente fria pelo centro do RS e oceano Atlântico adjacente, até uma área de baixa pressão relativa de $996 \mathrm{hPa}$. A MPA, com valores de pressão em torno de $1024 \mathrm{hPa}$, já se encontra deslocada para o nordeste do estado, o registro de chuva fraca de aproximadamente 3,0 $\mathrm{mm}$ para Santa Maria no início e no fim do dia (Figura 4 A e B).

$O$ gráfico da análise rítmica (Figura $5 \mathrm{~A}$ ) não registra precipitação para o dia 04 em função da escala de análise em função do baixo volume registrado, porém é perceptível, tanto no gráfico de análise rítmica do tempo atmosférico, quanto nos gráficos de temperatura máxima e mínima, uma redução expressiva da temperatura, registrando-se um decréscimo de aproximadamente 10 ㅇ C entre o dia anterior e o dia 04 de agosto (Figura 5C).

É possível observar no gráfico da análise rítmica e no gráfico da pressão atmosférica, um aumento significativo dos valores de pressão sobre Santa Maria em torno de 1008 hPa (Figura 5D), e valores de umidade relativa em elevação, chegando a $100 \%$ durante às primeiras horas do dia (Figura 6C).

Quanto aos padrões de velocidade e direção do vento é possível observar uma diminuição na velocidade média do vento no decorrer do dia 04 em relação ao dia 03, e uma mudança significativa na direção que passa do setor norte no dia 03, para sudoeste no dia 04 (Figura 6B) 
GOBO,J.P.A., ALVES,R.R., SILVEIRA,T.S., ONÇA,D.S.,MONTEIRO,L.M., WOLLMANN,C.A. e GALVANI,E. A INFLUÊNCIA DO VENTO REGIONAL NA SENSAÇÃO TÉRMICA DE PEDESTRES EM ESPAÇOS URBANOS ABERTOS: ESTUDO DE CASO DO VENTO NORTE EM SANTA MARIA-RS

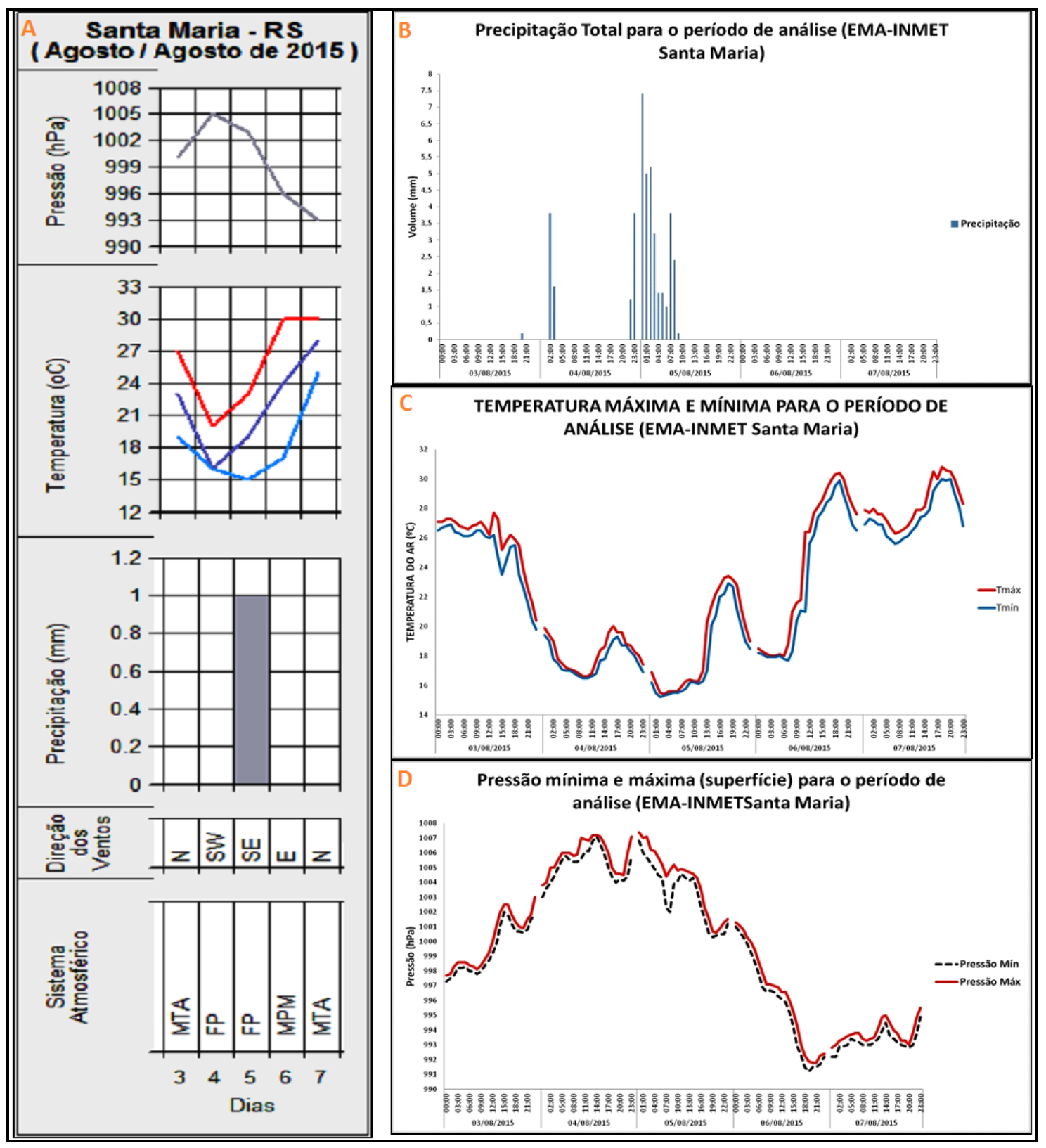

Figura 05 - Análise rítmica e interpretação dos atributos climáticos para o período de trabalho de campo em Santa Maria-RS.Fonte: EMA-INMET Santa Maria.

No dia 05 de agosto, é possível observar um cavado ao sul do Paraguai e sobre o estado do Rio Grande do Sul, o que configura baixas pressões em altos níveis da atmosfera e, consequentemente, precipitação (Figura 7A). Observa-se muita nebulosidade sobre o Rio
Grande do Sul e também duas frentes frias, sendo uma localizada em aproximadamente $48^{\circ} \mathrm{S}$ e $78^{\circ} \mathrm{W}$ com centro de baixa pressão relativa de $988 \mathrm{hPa}$, e outra em $38^{\circ} \mathrm{S}$ e $75^{\circ} \mathrm{W}$ com área de baixa pressão relativa de $1000 \mathrm{hPa}$, já em aproximação com o Sul do Brasil (Figura 7A e B). 


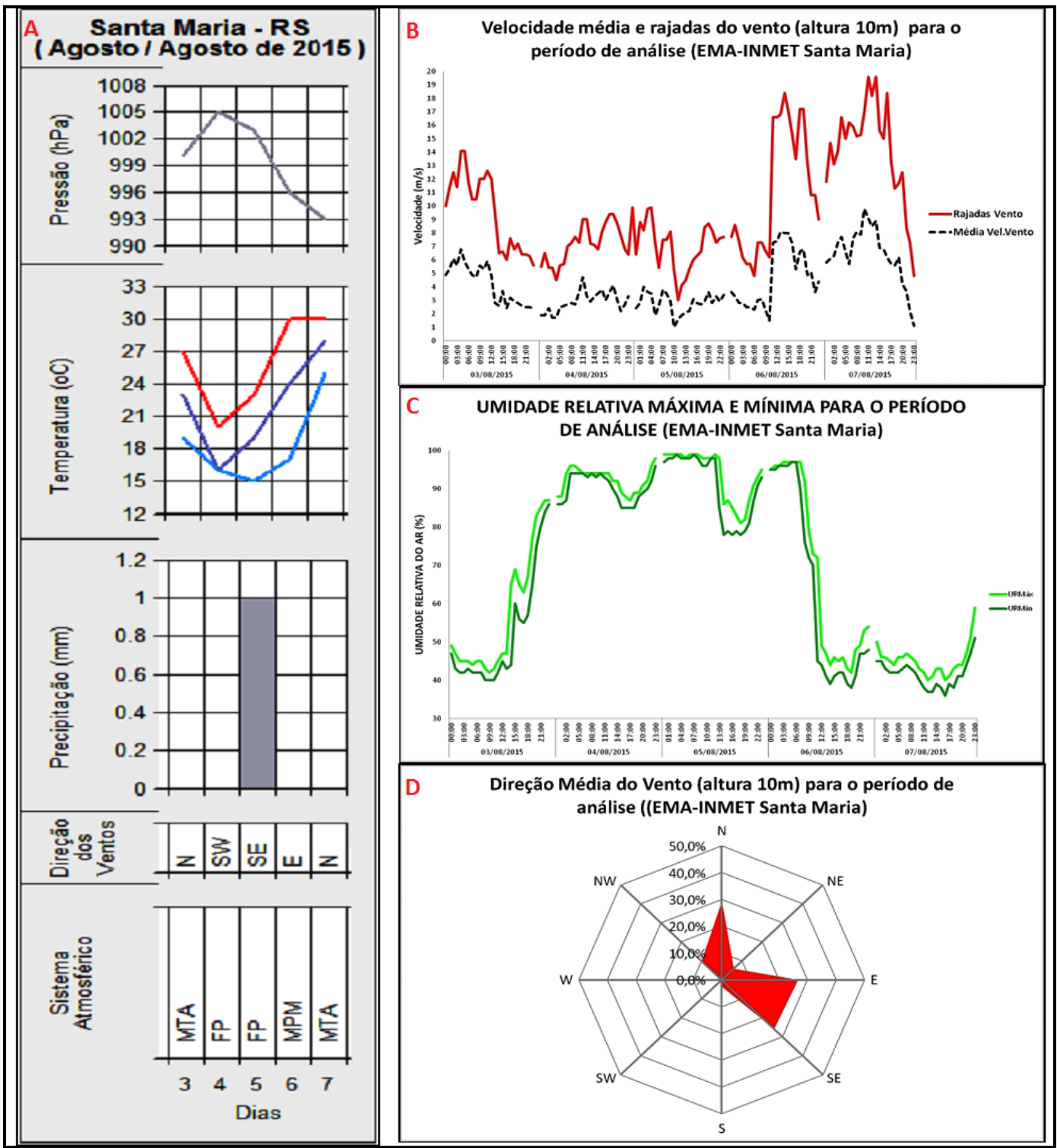

Figura 06 - Análise rítmica e interpretação dos atributos climáticos para o período de trabalho de campo em Santa Maria-RS.Fonte: EMA-INMET Santa Maria.

O gráfico de precipitação da figura 5B apresenta o maior volume acumulado de precipitação para o dia 05 de agosto, o que, em uma primeira análise, não vem de encontro com os níveis elevados de pressão atmosférica e temperaturas relativamente mais baixas, como é observado nos gráficos e na análise rítmica. Porém, esta precipitação justifica-se pelo cavado observado nas cartas sinóticas do dia 05 de agosto na figura 7A, apesar de neste dia, a situação atmosférica estar sob domínio da Massa Polar Modificada (MPM), que caracteriza-se pelo processo de tropicalização de suas características, perdendo em partes as propriedades polares que a configuram.

$\mathrm{Na}$ análise do dia 06 e 07 de agosto, observam-se situações sinóticas semelhantes com a presença de uma frente fria a leste de $30^{\circ} \mathrm{W}$, entre os paralelos de $20^{\circ} \mathrm{S}$ e $30^{\circ} \mathrm{S}$ (Figura 7A) e uma área de baixa pressão relativa a 1004 $\mathrm{hPa}$ localizada em aproximadamente $36^{\circ} \mathrm{S}$ e $72^{\circ} \mathrm{W}$, configurando novamente ao Rio Grande do Sul uma situação de tempo pré-frontal que se estende durante os dias 06 e 07 de agosto 
GOBO,J.P.A., ALVES,R.R., SILVEIRA,T.S., ONÇA,D.S.,MONTEIRO,L.M., WOLLMANN,C.A. e GALVANI,E. A INFLUÊNCIA DO VENTO REGIONAL NA SENSAÇÃO TÉRMICA DE PEDESTRES EM ESPAÇOS URBANOS ABERTOS: ESTUDO DE CASO DO VENTO NORTE EM SANTA MARIA-RS

caracterizada pela elevação das temperaturas máximas e mínimas (Figura 5C), diminuição da pressão atmosférica (Figura 5D) e da umidade relativa do ar (Figura $6 \mathrm{C}$ ), bem como a mudança nos padrões de vento que agora configuram-se com velocidades elevadas e provenientes do quadrante leste e norte (Figura 6B e D), movidos pelo gradiente de pressão formado entre as baixas pressões localizadas na Argentina e as altas pressões da MTA do sudeste do Brasil.

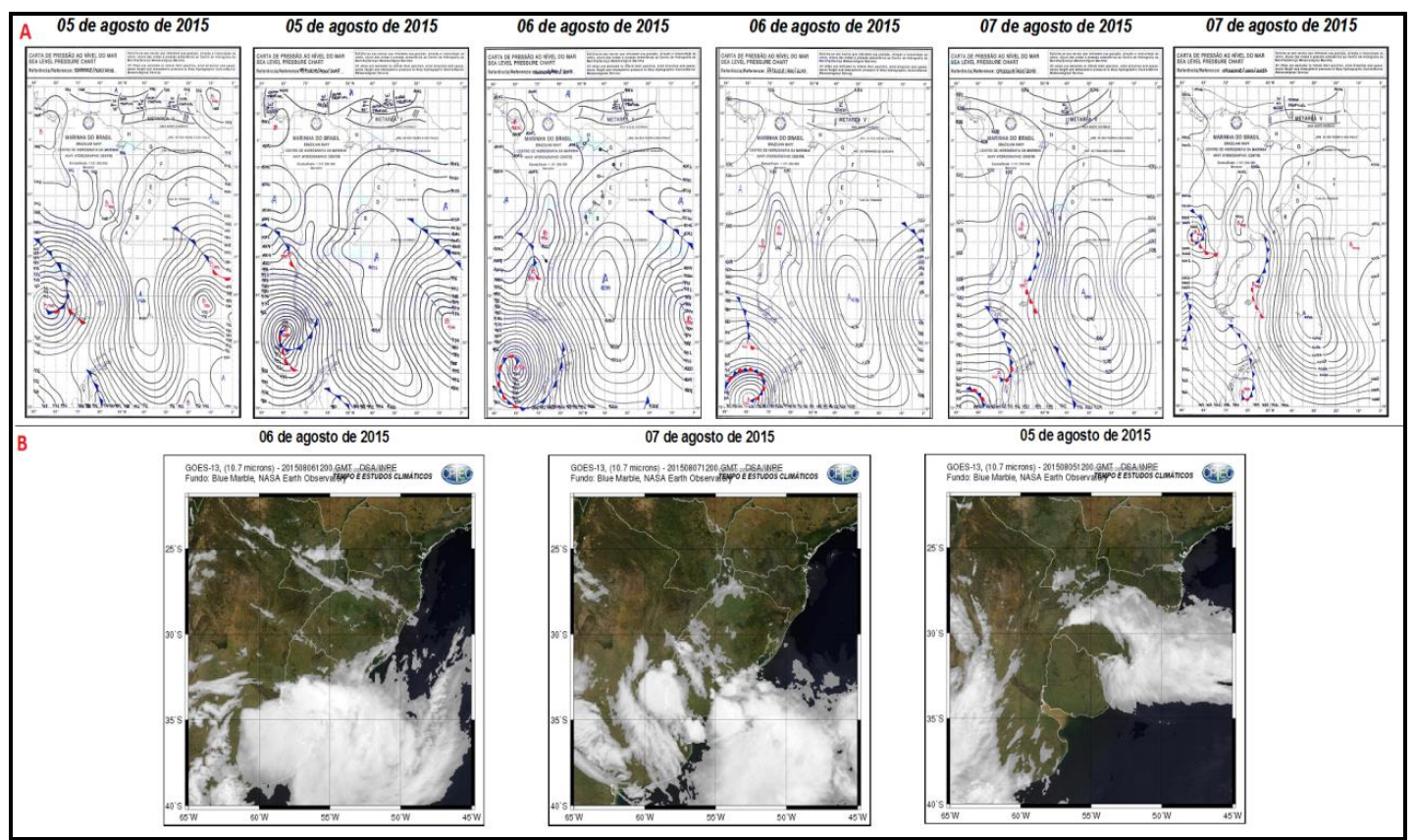

Figura 07 - A - Cartas sinóticas de superfície dos dias 5, 6 e 7 de agosto de 2015. B - Imagens do satélite Goes12 para os dias 5, 6 e 7 de agosto de 2015. Fonte: A - CPTEC/INPE (2015). B - Marinha do Brasil (2015).

Foram nesses dias (06 e 07 de agosto) onde se observou com maior preponderância o episódio de Vento Norte. A partir do gráfico da velocidade média e das rajadas do vento na figura 6B, é possível observar rajadas de até $20 \mathrm{~m} / \mathrm{s}$ nas primeiras horas dos dias observados, com diminuição da velocidade média e, consequentemente, das rajadas à medida que decorre o dia e há o aquecimento radiativo da superfície, o que é característico de um vento catabático como o vento norte (SARTORI, 2000; DALLA FAVERA, et al., 2012; MILLER, 1968; PERETTI; SARTORI, 2001; GOBO, et. Al., 2008).

Enquanto no segundo e no terceiro dia o tempo atmosférico foi caracterizado pelo domínio da Frente Polar (FP) e da Massa Polar Modificada (MPM) respectivamente, com características de umidade relativa do ar elevada e temperaturas em declínio, com vento do quadrante sul e sudoeste, nos dois últimos dias retorna o domínio de uma situação pré-frontal sobre o Rio Grande do Sul, caracterizando elevação nas temperaturas, diminuição da pressão atmosférica e da umidade relativa do ar, bem como mudança na direção e velocidade do vento.

Estes padrões climatológicos observados configuram uma situação de tempo anômala em relação aos padrões típicos para o mês de agosto em pleno inverno na região, com temperaturas muito acima da normal climatológica (1961-1990) de Santa Maria (Figura 8). 


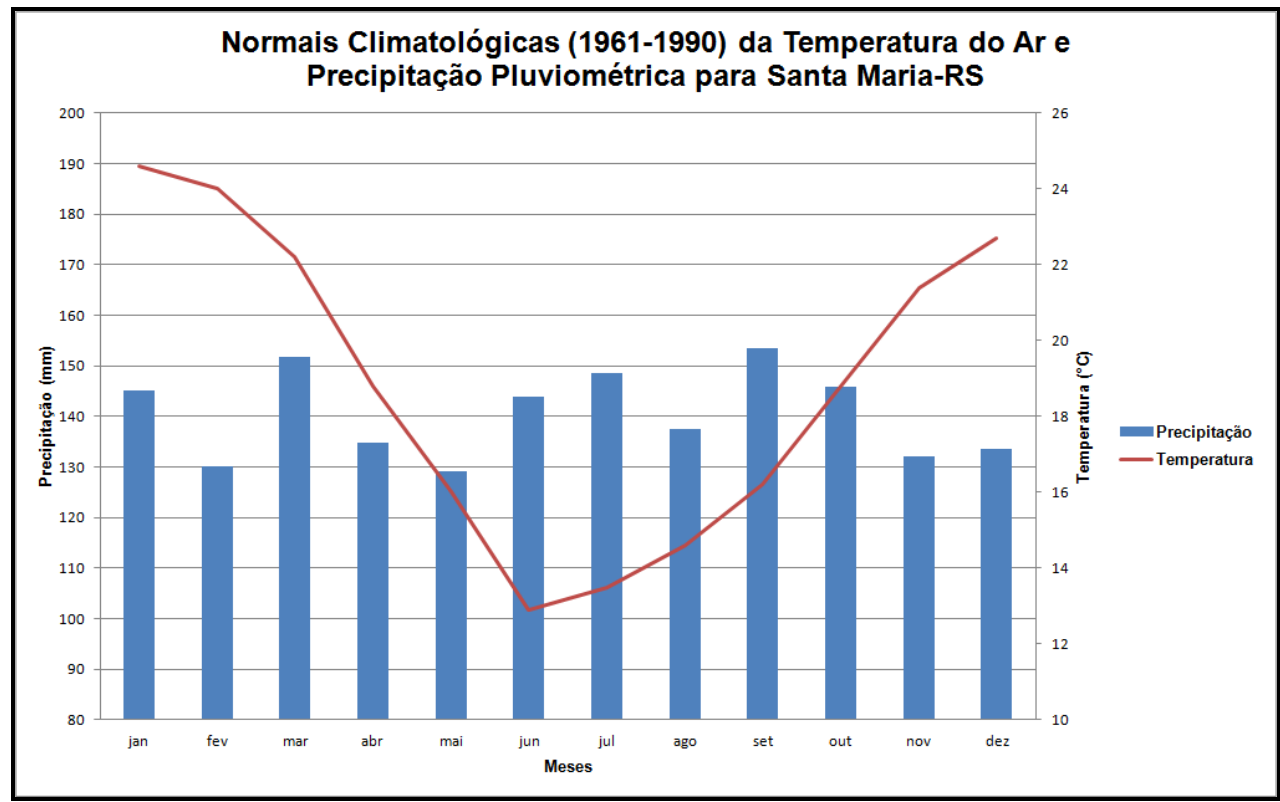

Figura 08 - Normais climatológicas (1961-1990) da temperatura do ar e precipitação pluviométrica para Santa Maria - RS. Fonte: Instituto Nacional de Meteorologia (INMET) (2016).

\subsection{ANÁLISE CLIMÁTICA EM ESCALA LOCAL}

$\mathrm{Na}$ análise dos dados meteorológicos coletados em campo no período de 03 a 07 de agosto, observa-se um padrão muito semelhante aos dados da EMA-INMET de Santa Maria, porém, com algumas variações características da área urbana e, também pelo fato de os dados da EMA-Móvel que haviam sido coletados em um intervalo de 10 (dez) minutos, o que aumenta a resolução dos dados, permitindo uma análise mais detalhada das variações dos elementos climáticos (temperatura do ar, umidade relativa do ar, direção e velocidade do vento, radiação solar e precipitação) em campo. Chama-se atenção, também, para o fato de que os dados coletados durante $o$ trabalho de campo restringem-se ao período de 09:00h às 17:00h.

Em relação temperatura do ar e umidade relativa do ar para a série completa (Figura 9A e C) há uma semelhança bem definida com os dados dos mesmos elementos climáticos analisados para o clima regional por meio da EMA-INMET (Figura 6 e 7).

Nota-se que, tanto a temperatura do ar quanto a umidade relativa do ar, obedecem ao padrão da dinâmica atmosférica regional, com temperaturas elevadas e umidade relativa baixa nos períodos pré-frontais analisados (03, 06 e 07 de agosto) e com diminuição da temperatura seguida de aumento da umidade relativa do ar para o período frontal e de domínio da MPM (04 e 05 de agosto). Estes padrões foram observados por Galvani e Azevedo (2012) em estudo sobre a variação dos elementos meteorológicos e tipos de tempo associados à aproximação e passagem da frente polar atlântica em São Paulo.

A partir de uma análise horária dos atributos climáticos coletados no trabalho de campo, pode se observar o pico de maior temperatura do ar para a série no período das 15:00h, em conformidade com o período de mínima umidade relativa do ar horária da série. Já a temperatura do ar mínima horária é observada às 09:00h, e a umidade relativa do ar máxima horária revela-se as 17:00h, ambos os horários de início e fim, respectivamente, das medidas em campo (Figura 9B). 


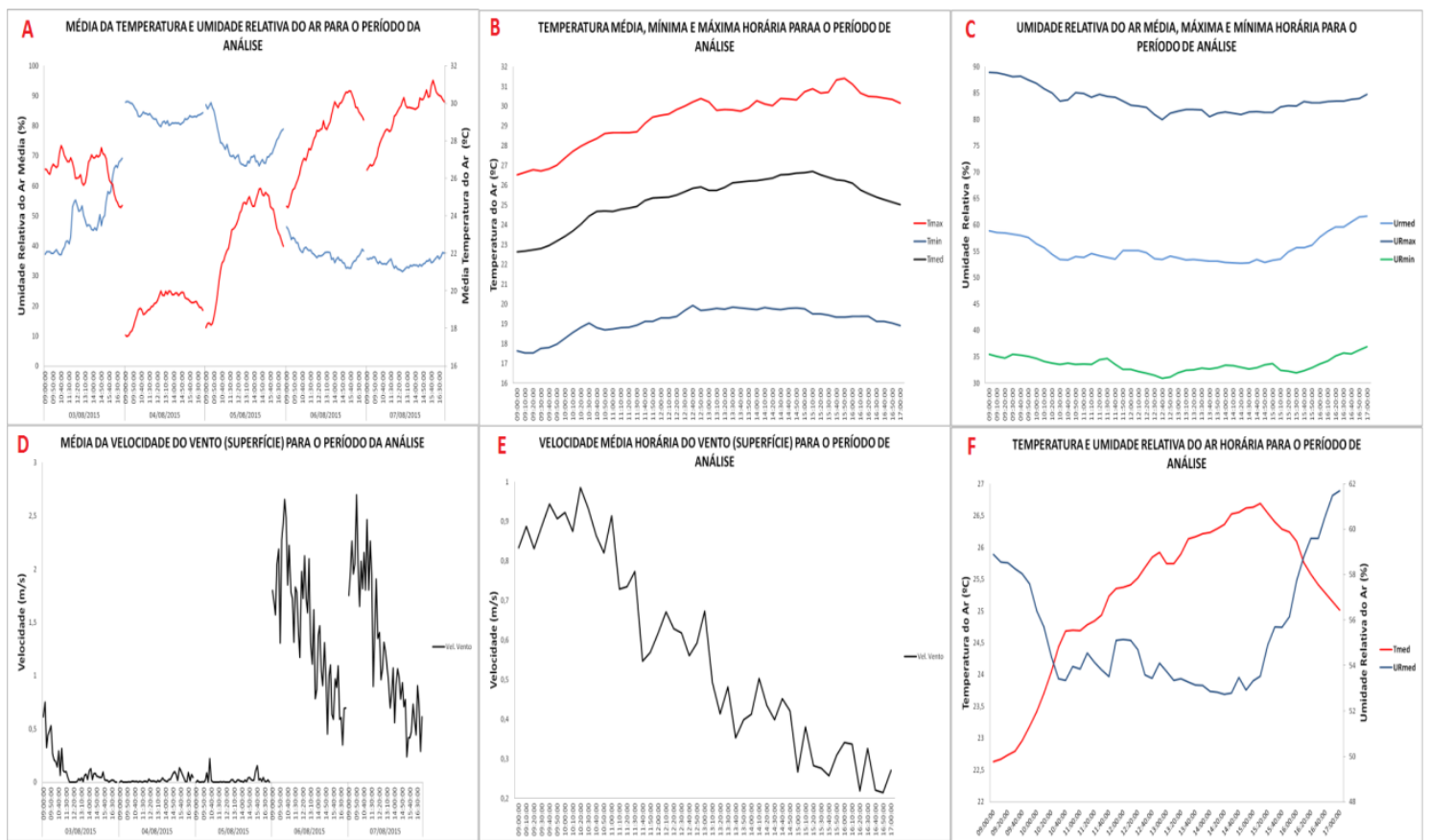

Figura 09 - Interpretação dos atributos climáticos para o período de trabalho de campo em Santa MariaRS. Fonte: Os autores.

Como já havia sido observado anteriormente, os padrões de vento, durante o período de análise, apresentaram episódio de vento norte nos dois últimos dias de coleta de dados, o que, além das temperaturas acima da média da normal climatológica para o período, interfere diretamente nas respostas preditivas da população, bem como no resultado dos índices de conforto térmico.

Nota-se nos gráficos da velocidade média do vento para a série completa, bem como para a análise horária, que há um predomínio do vento mais intenso nas primeiras horas do dia (Figura 9D e E), o que já havia sido observado nos dados da EMA-INMET (Figura 6). Esta característica se dá em face do resfriamento noturno menos acentuado nas áreas ao sopé do rebordo do Planalto da Bacia do Paraná, onde se localiza a área urbana do município de Santa Maria, em contraste com o resfriamento mais intenso das áreas mais altas do rebordo, configurando um gradiente de pressão que possibilita o aumento das rajadas e da velocidade média do vento norte nesse período (SARTORI, 2016).
Por outro lado, à medida que se inicia o aquecimento da superfície pelo sol no decorrer do dia, há um aumento da temperatura do ar nas áreas a sopé do rebordo do planalto em relação às áreas mais elevadas, diminuindo o gradiente de pressão, porém não há inversão deste gradiente como observa-se em regiões de brisa vale-montanha.

Durante os dias anteriores de observação (03, 04 e 05), o vento não apresentou velocidade média mais expressiva, mesmo em face da chegada de um sistema frontal no dia 04.

\subsection{ANÁLISE DA INFLUÊNCIA DO VENTO NORTE NO CONFORTO TÉRMICO HUMANO}

Assim como nos trabalhos de Pantavou, et al. (2013), Chen, et al. (2010) e Xi, et al. (2012), obedeceu-se um padrão médio de entrevistas, com a finalidade de entrevistar igualitariamente homens e mulheres, sendo que em sua maioria estivessem na faixa dos 30 anos de idade, para fins de manter o máximo de características próximas ao ser humano saudável com organismo em equilíbrio metabólico (aproximadamente 35 anos). 
GOBO,J.P.A., ALVES,R.R., SILVEIRA,T.S., ONÇA,D.S.,MONTEIRO,L.M., WOLLMANN,C.A. e GALVANI,E. A INFLUÊNCIA DO VENTO REGIONAL NA SENSAÇÃO TÉRMICA DE PEDESTRES EM ESPAÇOS URBANOS ABERTOS: ESTUDO DE CASO DO VENTO NORTE EM SANTA MARIA-RS

A tabela 1 apresenta alguns dados entrevistados durante os 5 dias de análise. qualitativos acerca do perfil médio dos populares

Tabela 01 - Sensação térmica da população de Santa Maria para os dias de trabalho de campo

\begin{tabular}{c|cccccc} 
& \multicolumn{3}{|c}{ Masculino } & \multicolumn{3}{c}{ Feminino } \\
\cline { 2 - 7 } & \multicolumn{3}{|c}{ Total absoluto: 702} & \multicolumn{3}{c}{ Total absoluto: 725} \\
\cline { 2 - 7 } & Médio & Máximo & Mínimo & Médio & Máximo & Mínimo \\
\hline Idade (anos) & 33 & 60 & 18 & 32 & 60 & 18 \\
Altura (m) & 1,75 & 1,99 & 1,55 & 1,63 & 1,82 & 1,48 \\
Peso (kg) & 78 & 125 & 62 & 63 & 98 & 40
\end{tabular}

Fonte: Os Autores

No entanto, os trabalhos de Chen, et al. (2010) e Xi, et al. (2012) foram executados em campus de universidades, com um número mais restrito de indivíduos entrevistados, e com um padrão médio um pouco mais jovem.

Outra diferença em relação aos trabalhos citados é que a presente pesquisa partiu de uma abordagem transversal, tal qual o trabalho de $\mathrm{Ng}$ e Cheng (2012), quando pessoas diversas são entrevistadas sem que essas entrevistas se repitam com os mesmos indivíduos. Este método tem a vantagem de observar o maior numero e mais diversos votos de predições individuais possíveis, fornecendo uma maior confiabilidade aos resultados devido ao tamanho da amostragem, porém é um método que requer um número relativamente grande de indivíduos abordados.

Para uma melhor visualização e interpretação dos resultados, a tabela 2 apresenta os valores médios de temperatura média, máxima e mínima diária, bem como os valores médios de umidade relativa do ar média máxima e mínima diária. Também é apresentado na tabela 2 os valores de velocidade média diária e velocidade máxima diária do vento para o período de análise

Tabela 02 - Elementos climáticos coletados em campo pela estação meteorológica móvel durante o período de análise.

\begin{tabular}{c|cccccccc}
$\begin{array}{c}\text { Dias de } \\
\text { Campo }\end{array}$ & $\begin{array}{c}\text { Temp. } \\
\text { Máx. }\end{array}$ & $\begin{array}{c}\text { Temp. } \\
\text { Mín. }\end{array}$ & $\begin{array}{c}\text { Temp. } \\
\text { Méd. }\end{array}$ & $\begin{array}{c}\text { UR } \\
\text { Máx. }\end{array}$ & $\begin{array}{c}\text { UR } \\
\text { Méd. }\end{array}$ & $\begin{array}{c}\text { UR } \\
\text { Mín. }\end{array}$ & $\begin{array}{c}\text { Vel. Méd. } \\
\text { do Vento }\end{array}$ & $\begin{array}{c}\text { Vel. Máx. } \\
\text { do Vento }\end{array}$ \\
\hline $03 / 08 / 2015$ & 27,8 & 24,4 & 26,4 & 69,4 & 48,9 & 36,3 & 0,1 & 3,0 \\
$04 / 08 / 2015$ & 20,1 & 17,5 & 19,2 & 88,9 & 83,1 & 79,4 & 0,0 & 1,0 \\
$05 / 08 / 2015$ & 25,7 & 18,0 & 22,9 & 88,2 & 73,1 & 65,0 & 0,0 & 1,1 \\
$06 / 08 / 2015$ & 30,7 & 24,4 & 28,4 & 47,2 & 37,6 & 32,0 & 1,4 & 8,8 \\
$07 / 08 / 2015$ & 31,4 & 26,4 & 29,3 & 38,2 & 34,4 & 30,9 & 1,3 & 8,3
\end{tabular}

Fonte: Os Autores

Os resultados observados ao fim do levantamento mostraram que, para a escala da ASHRAE/ANSI 55 (2013), nos três primeiros dias de entrevistas (03, 04 e 05 de agosto), a maior parte dos indivíduos não estava sentindo nem frio nem calor, enquanto nos dois últimos dias (06 e 07 de agosto) a maioria das pessoas entrevistadas estava sentindo calor (Tabela 3).
Observou-se a frequência dos votos de sensação térmica da população para a série completa de análise em comparação com os resultados dos índices de "Temperatura Efetiva com Vento" (TEv) de Suping . (1992) (Figura 10).

O gráfico da figura 10 mostra um índice TEv mais elevado durante os 3 primeiros dias, o que pode ser explicado pela velocidade relativamente baixa do vento nesses dias, bem 
GOBO,J.P.A., ALVES,R.R., SILVEIRA,T.S., ONÇA,D.S.,MONTEIRO,L.M., WOLLMANN,C.A. e GALVANI,E. A INFLUÊNCIA DO VENTO REGIONAL NA SENSAÇÃO TÉRMICA DE PEDESTRES EM ESPAÇOS URBANOS ABERTOS: ESTUDO DE CASO DO VENTO NORTE EM SANTA MARIA-RS

como o aumento expressivo dos valores de umidade relativa do ar nos dias 04 e 05 de agosto, em função da passagem do sistema frontal.

Tabela 03 - Sensação térmica da população de Santa Maria para os dias de trabalho de campo

\begin{tabular}{|c|c|c|c|c|c|c|c|c|c|c|}
\hline \multirow[b]{2}{*}{ DIAS } & \multicolumn{7}{|c|}{$\begin{array}{c}\text { Escala } \\
\text { ASHRAE/ANSI } 55 \text { (2004) }\end{array}$} & \multirow[t]{2}{*}{$\begin{array}{l}\text { Total } \\
\text { geral }\end{array}$} & \multirow[t]{2}{*}{$\begin{array}{l}\text { Número } \\
\text { Máximo de } \\
\text { Ocorrência }\end{array}$} & \multirow[t]{2}{*}{$\begin{array}{c}\text { Valor Máximo } \\
\text { Predito da Escala } \\
\text { ASHRAE/ANSI } 55\end{array}$} \\
\hline & 3 & -2 & -1 & 0 & 1 & 2 & 3 & & & \\
\hline 03/08/2015 & 1 & 1 & 3 & 99 & 87 & 81 & 16 & 288 & 99 & 0 \\
\hline 04/08/2015 & & 5 & 55 & 155 & 54 & 14 & & 283 & 155 & 0 \\
\hline 05/08/2015 & & 2 & 8 & 127 & 76 & 69 & 6 & 288 & 127 & 0 \\
\hline 06/08/2015 & & & 2 & 79 & 84 & 97 & 20 & 282 & 97 & 2 \\
\hline $07 / 08 / 2015$ & & & & 71 & 59 & 135 & 23 & 288 & 135 & 2 \\
\hline Total geral & 1 & 8 & 68 & 531 & 360 & 396 & 65 & 1429 & & \\
\hline
\end{tabular}

Fonte: Os Autores

Já nos dois últimos dias de trabalho de campo, observa-se a partir do gráfico da figura 10 um aumento valores dos índices TEv, isto se deu em função da situação sinótica definida anteriormente para os dias 06 e 07 de agosto com episódio de vento norte bem definido em função de uma situação de tempo pré-frontal, com aquecimento atmosférico e declínio dos valores de pressão e umidade relativa do ar.

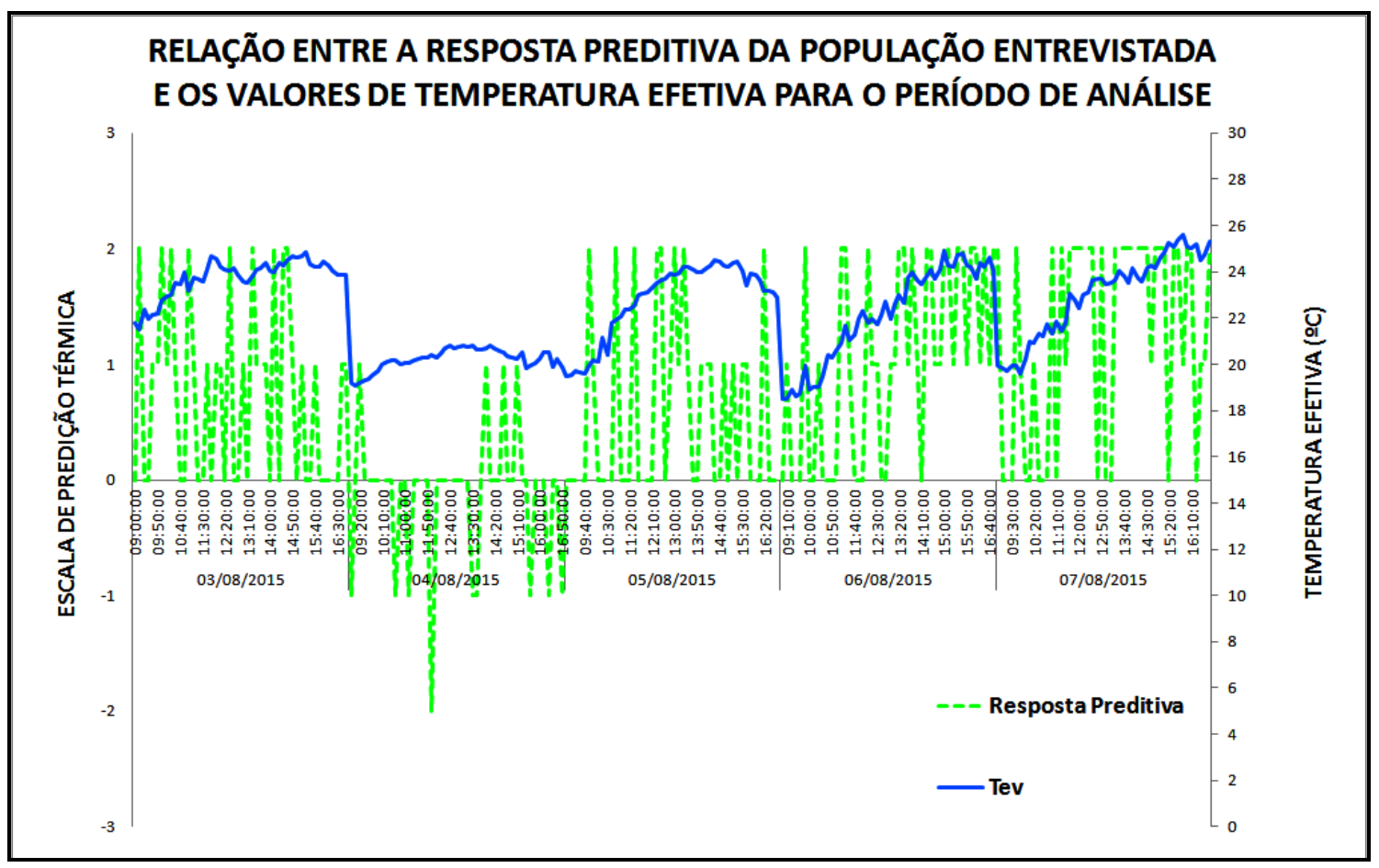

Figura 10 - Gráfico comparativo entre a resposta percebida dos indivíduos entrevistados e os índices de conforto térmico para o período de análise.Fonte: Os autores.

Sabe-se que esse comportamento do índice TEv também já foi observado nos trabalhos de Santos (2014), Gobo et al. (2015a; 2015b) e Nedel et al. (2009), onde os autores verificaram que, quando em relação da velocidade do vento e da temperatura do ar, o TEv apresenta melhores resultados. 
GOBO,J.P.A., ALVES,R.R., SILVEIRA,T.S., ONÇA,D.S.,MONTEIRO,L.M., WOLLMANN,C.A. e GALVANI,E.

\section{A INFLUÊNCIA DO VENTO REGIONAL NA SENSAÇÃO TÉRMICA DE PEDESTRES EM ESPAÇOS URBANOS ABERTOS: ESTUDO DE CASO DO VENTO NORTE EM SANTA MARIA-RS}

Durante estes dois últimos dias a frequência de votos de sensação térmica da população foi para calor e é notório que, mesmo em função do vento, não houve arrefecimento da temperatura do ar, o que se justifica pelo vento norte ser quente e seco, o que, em determinados casos, pode vir a ser um fato ainda maior de desconforto para a população.

O gráfico da figura 11 apresenta a sensação térmica diária e horária da população de Santa Maria para o período estudado, com ampla diferença dos dois últimos dias de análise em relação aos três primeiros dias. Essa diferença também pode ser observada na tabela 2 , onde os valores médios dos atributos climáticos coletados pela estação meteorológica móvel são apresentados.

No dia 03 de agosto, 99 de 288 indivíduos, não estavam sentindo nem frio nem calor, frente à situação atmosférica pré-frontal para o dia, com temperatura média de 26,4으 (Tabela 2), o que corresponde a $34,3 \%$ do total (Figura 11), enquanto no dia 04 de agosto, durante a passagem do sistema frontal, o número de pessoas satisfeitas era de 155 de 283 (Tabela 3), o que corresponde a $54,7 \%$ do total de entrevistados (Figura 11). Neste dia, a temperatura do ar média foi de 19,2 ㄷ e mínima de 17,5 으. Diferentemente do dia 03, no dia 04 a grande maioria dos entrevistados estavam satisfeitos.

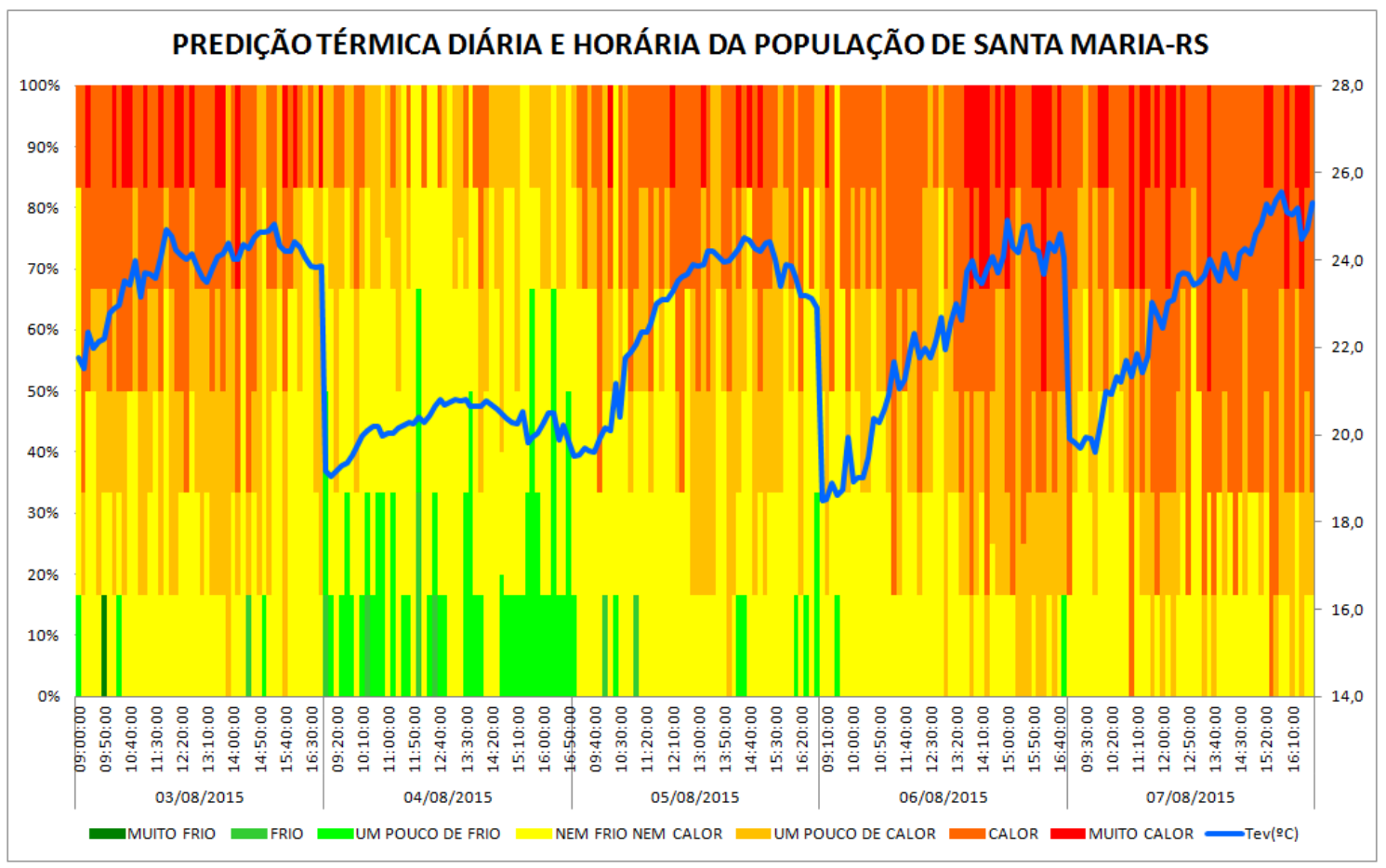

Figura 11 - Gráfico da porcentagem diária e horária da sensação térmica dos indivíduos entrevistados em campo em comparação com o Índice de Temperatura Efetiva com Vento (TEv). Fonte: Os autores.

No dia 05 de agosto 127 pessoas relataram não estar sentindo nem frio nem calor, de um total de 288 (Tabela 3). Esses indivíduos satisfeitos correspondem a $44 \%$ do total de entrevistados (Figura 11), o que demonstra, assim como no dia 03, que apesar da frequência de indivíduos satisfeitos neste dia ser maior, eles não eram a maioria absoluta, assim como no dia
04. Neste dia a temperatura média do ar no centro da cidade era de 22,9 ㅇ․

O dia 06 de agosto apresentou um número mais igualitário de pessoas não sentindo nem frio nem calor, um pouco de calor e calor, porém a maior frequência de votos preditivos foi para a sensação de calor, com 97 votos de um total de 282 , o que corresponde a $34,3 \%$ do total de entrevistados. Neste dia a situação 
GOBO,J.P.A., ALVES,R.R., SILVEIRA,T.S., ONÇA,D.S.,MONTEIRO,L.M., WOLLMANN,C.A. e GALVANI,E.

\section{A INFLUÊNCIA DO VENTO REGIONAL NA SENSAÇÃO TÉRMICA DE PEDESTRES EM ESPAÇOS URBANOS ABERTOS: ESTUDO DE CASO DO VENTO NORTE EM SANTA MARIA-RS}

atmosférica era novamente caracterizada por uma situação pré-frontal, com domínio da MPM e com temperatura média diária de $28,0 \mathrm{C}$ e episódio de vento norte bem definido durante 0 período da coleta dos dados no centro de Santa Maria, com velocidade máxima registrada de 8,8 $\mathrm{m} / \mathrm{s}$. Deve-se ressaltar que as aferições realizadas pela estação meteorológica móvel foram feitas a cada 10 minutos, o que não caracteriza os dados instantâneos, subestimando, neste caso, os valores de rajada do vento.

Mais uma vez a maior frequência de um determinado voto preditivo não correspondeu à maioria absoluta, o que demonstra uma fragilidade metodológica a ser observada e repensada no decorrer desta pesquisa.

No dia 07 de agosto, novamente a maior frequência do voto predito não correspondeu à maioria absoluta, porém a porcentagem foi mais significativa do que no dia anterior com 135 pessoas de 288 afirmando estar sentindo calor, o que corresponde a $48 \%$ do total (Figura 11). Neste dia a temperatura média do ar era de 29,3 으 e o tempo caracterizava-se pelo predomínio da MTA, com episódio de vento norte bem definido e velocidade máxima do vento registrada de $8,3 \mathrm{~m} / \mathrm{s}$, o que poderia, em tese, ter amenizado o desconforto por calor dos indivíduos entrevistados.

Quanto à percepção climática da população de Santa Maria em relação ao vento norte que se intensificou nos dois últimos dias de análise, o gráfico da figura 12 apresenta a porcentagem das preferências percebidas pelos pedestres.

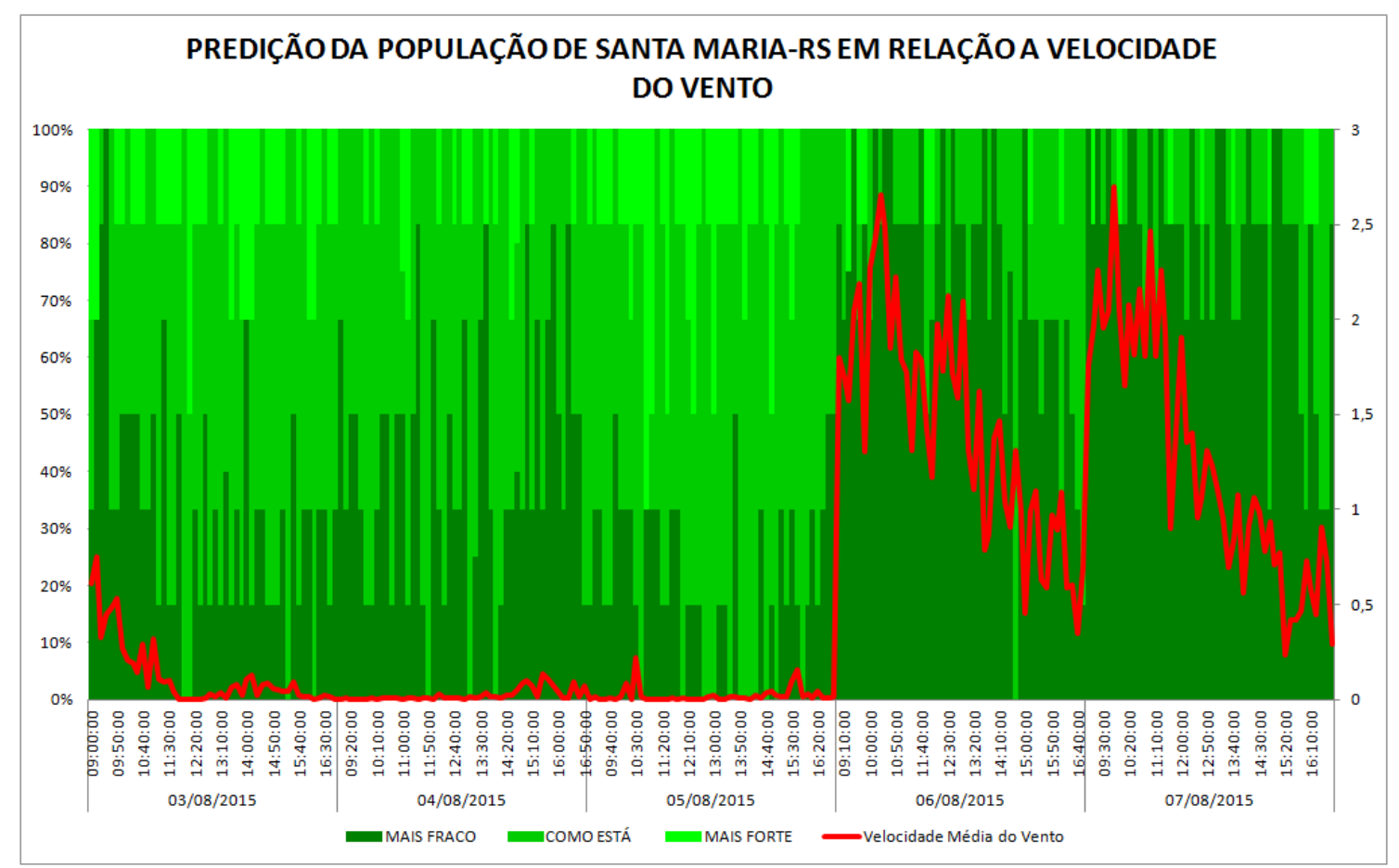

Figura 12 - Gráfico da porcentagem diária e horária da percepção dos indivíduos entrevistados em campo em relação ao vento norte e a velocidade média do vento. Fonte: Os autores.

Observa-se que nos três primeiros dias há uma maior preferência por velocidade do vento mantendo-se como estava, enquanto nos dois últimos dias houve uma preferência maior por velocidade do vento mais fraca, em virtude da ação do vento norte durante estes dias.

Faz-se necessário salientar que as respostas da população quanto à sensação térmica, comparadas às respostas perceptivas 
GOBO,J.P.A., ALVES,R.R., SILVEIRA,T.S., ONÇA,D.S.,MONTEIRO,L.M., WOLLMANN,C.A. e GALVANI,E.

\section{A INFLUÊNCIA DO VENTO REGIONAL NA SENSAÇÃO TÉRMICA DE PEDESTRES EM ESPAÇOS URBANOS ABERTOS: ESTUDO DE CASO DO VENTO NORTE EM SANTA MARIA-RS}

acerca da velocidade do vento, onde há uma sensação de "calor" e "muito calor" nos dois últimos dias mesmo havendo vento norte.

Este padrão de desconforto excessivo causado pela combinação de altas temperaturas em um período de inverno associadas a um intenso e constante vento de velocidade elevada caracterizando-se por ser seco e quente vêm de encontro aos trabalhos de Bedford e Warner (1934), Sorre (1984), Sartori (2000, e 2016), Peretti e Sartori (2001) e Gobo, et al. (2008).

\section{CONSIDERAÇÕES FINAIS}

Em face dos dados coletados em campo e em função da situação atmosférica anômala observada durante o trabalho de campo em agosto de 2015, verificou-se uma influência negativa do vento norte na sensação térmica da maioria dos indivíduos entrevistados, bem como uma percepção desfavorável ao vento.

A avaliação apontou grande desconforto durante os dias em que as temperaturas superaram os $25 \circ \mathrm{C}$, em função, principalmente da ilha de calor urbana, que é fortemente influenciada pelos materiais do entorno, e do vento norte quente e seco que intensifica ainda mais o desconforto da população que ocupa estas áreas.

Foi possível observar que as sensações de conforto e desconforto térmico durante os dias de estudo não se limitaram apenas às variáveis microclimáticas e foram fortemente influenciadas pelas variáveis do clima regional, principalmente em função do vento norte e da passagem da Frente Polar Atlântica.

Ficou constatada a relação praticamente inversa entre os valores de temperatura do ar e velocidade do vento durante os episódios de vento norte nos dois últimos dias da pesquisa.

Este estudo pode servir de base para um futuro planejamento das áreas centrais urbanas da cidade, visando uma melhora no fluxo e circulação do ar intraurbano, bem como uma maior disposição de áreas sombreadas.

\section{AGRADECIMENTOS}

Os autores agradecem a ao CNPq, ao Departamento de Geografia da Universidade Federal de Santa Maria - UFSM e ao Laboratório de Conforto Ambiental e Eficiência Energética do Departamento de Tecnologia da Arquitetura da FAU-USP.

\section{REFERÊNCIAS}

ANSI/ASHRAE Standard 55.; Thermal Environmental Conditions for Human Occupancy. Atlanta: American society of heating, refrigerating, and air-conditioning engineers. 2013.

BEDFORD, T.; WARNER, C.; The globe thermometer in studies of heating and ventilation. Journal of Hygiene, v.34, p.458-473, 1934.

BORSATO, V. A. BORSATO F. H e SOUSA E. E., Análise Rítmica e a Variabilidade Têmporo Espacial. In: VI Simpósio Brasileiro de Climatologia Geográfica. Anais. Teoria e Metodologia em Climatologia. Universidade Federal de Sergipe, Núcleo de pós Graduação Geográfica, Aracajú SE. Outubro 2004. Eixo 3 tema 3 - CD-ROM.

CHENG, V.; NG, E.; CHAN, C.; GIVONI, B.; Outdoor thermal comfort study in sub-tropical climate: $A$ longitudinal study based in Hong Kong. International Journal of Biometeorology. 2010.

DALLA FAVERA, A. C.; MARTINS, F. R.; Schuch, N. J.; PEREIRA, E. B.; LUIZ, E. W.; Potencial Eólico no Rio Grande Do Sul Distribuição Estatística dos Ventos na Região Central do Estado. Revista Geográfica Acadêmica, v. 6, p. 38-51, 2012.

DAL'ASTA, A. P.; PIRES, C. A. F.; Modelamento geoestatístico de parâmetros obtidos em sondagens de Simples reconhecimento na cidade de Santa Maria - RS. In: Anais. XII Simpósio Brasileiro de Geografia Física Aplicada, Natal. 2007.

FROTA, A.B., SCHIFFER, S.R. Manual de conforto térmico. 5 ed. São Paulo: Studio Nobel, 2001.

GALVANI, E.; AZEVEDO, T. R.; A frente polar atlântica e as características de tempo associadas: estudo de caso. In: Emerson Galvani, Nádia Gilma Beserra de Lima. (Org.). Climatologia Aplicada: Resgate aos estudos de caso. 1ed.Curitiba: Editora CRV, 2012, v. 1, p. 7-18.

GOBO, J. P. A.; MONTEBLANCO, F. L.; PORTES, G. S.; SARTORI, M. G. B.; O Vento Norte e os Índices de Violência Doméstica em Santa Maria-RS. In: 8o Simpósio Brasileiro de Climatologia Geográfica, 
GOBO,J.P.A., ALVES,R.R., SILVEIRA,T.S., ONÇA,D.S.,MONTEIRO,L.M., WOLLMANN,C.A. e GALVANI,E.

\section{A INFLUÊNCIA DO VENTO REGIONAL NA SENSAÇÃO TÉRMICA DE PEDESTRES EM ESPAÇOS URBANOS ABERTOS: ESTUDO DE CASO DO VENTO NORTE EM SANTA MARIA-RS}

Anais. Alto Caparaó. Evolução Tecnológica e Climatologia, 2008.

GOBO, J. P. A.; GALVANI, E.; WOLLMANN, C. A.; CELUPPI, M. C.; Estudo de zoneamento do conforto térmico humano para o Rio Grande do Sul: a inserção de anos-padrão como proposta metodológica. Ciência e Natura, v. 37, p. 451-470, 2015.

GOBO, J. P. A.; GALVANI, E.; WOLLMANN, C. A.; Regionalização bioclimática do Rio Grande do Sul: um estudo do conforto térmico humano em escala climática regional e sub-regional. Ciência e Natura, v. 37, p. 471-489, 2015.

Instituto Nacional de Meteorologia (INMET), 2016. São Paulo, SP, 2016. Disponível em: <www.inmet.gov.br>. Acesso em: 12 janeiro, 2016.

ISO 10551. Ergonomics of the Thermal Environment - Assessment of the Influence of the Thermal Environment Using Subjective Judgement Scales. International Organization for Standardization, Geneva. 1995.

ISO 7726. Ergonomics of the Thermal Environment - Instruments for Measuring Physical Quantities. International Organization for Standardization, Geneva. 1998.

ISO 8996. Ergonomics of the Thermal Environment - Determination of Metabolic Rate. International Organization for Standardization, Geneva. 2004.

ISO 9920. Ergonomics of the Thermal Environment - Estimation of Thermal Insulation and Water Vapour Resistance of a Clothing Ensemble. International Organization for Standardization, Geneva. 2007.

MACHADO, L. M. C. P. Paisagem valorizada - A Serra do Mar como espaço e como lugar. In.: OLIVEIRA, L de; DEL RIO, V. (Org.). Percepção ambiental - a experiência brasileira. São Paulo: Studio Nobel; São Carlos: Ed. da UFSCar, 1996. p. 96-119.

MARIANTE, H. M.; Meteorologia e astronomia populares no RS. Porto Alegre: Martins Livreiro Editor, 1985.

MILLER, W.; Santa Ana Winds and Crime. In: The Professional Geographer. Vol. XX (1) : 23-27, Association of Americam Geographer, 1968.

MONTEIRO, C. A. F. Teoria e clima urbano. São Paulo: Instituo de Geografia/USP, 1976. 181p. (Série Teses e Monografias, 25).

MÜLLER FILHO, I. L. Notas para o Estudo de Geomorfologia do Rio Grande do Sul, Brasil. Publicação Especial n. 1. Santa Maria: Imprensa Universitária. UFSM. 1970.
NEDEL, A. S.; TEIXEIRA, F. L. G.; CARDOSO, M. R. A.; Thermal simulation evaluation of residences in the metropolitan region of São Paulo, Brazil. Ecotoxicology and Environmental Safety, v. 18, p. 1143-1149, 2009.

NG, E.; CHENG, V.; Urban human thermal comfort in hot and humid Hong Kong. Energy Build. 55, 51-65. 2012.

NIKOLOPOULOU, M.; BAKER, N.; STEEMERS, K.; Thermal comfort in outdoor urban spaces: understanding the human parameter. Sol. Energy 70, 227-235. 2001.

PANTAVOU, K.; THEOHARATOS, G.; SANTAMOURIS, M.; ASIMAKOPOULOS, D.; Outdoor thermal sensation in a Mediterranean climate and a comparison with UTCI. Building and Environment 66, 82-95. 2013.

PERETTI, H. S., SARTORI, M. G. B.; Correlação entre uma variável climática e a prática de crimes contra a vida. In: IX Simpósio Brasileiro de Geografia Física e Aplicada. Recife, Anais... Recife, 2001. p. 226-227, 2001.

SANTOS, B. J.; AMORIM, R. F. C.; PEIXOTO, L.; Analise do conforto termico humano no município de Arapiraca, Alagoas, utilizando software MATLAB.. Revista Brasileira de Geofísica (Impresso), v. 7, p. 939-948, 2014.

SARTORI, M. G. B.; Clima e Percepção. USP/FFLCH (Tese de Doutoramento). São Paulo, 2000.

SARTORI, M. G. B.; O Vento Norte. Santa Maria: Editora DR Publicidade, 2016. 256 p.

SORRE, M.; Geografia (Tradução Januário F. Megele) São Paulo: Ática, 1984.

XI, T.; LI, Q.; MOCHIDA, A.; MENG, Q.; Study on the outdoor thermal environment and thermal comfort around campus clusters in subtropical urban areas. Build. Environ. 52, 162-170. 2012.

TUAN, Y-F. Topofilia. Tradução prefácio e notas: Lívia de Oliveira. São Paulo: DIFEL, [1980] 